\title{
ANALYTICAL TEM CHARACTERISATION OF CATALYTIC MATERIALS
}

\author{
D.S. $\mathrm{Su}^{*}$
}

Department of Inorganic Chemistry, Fritz-Haber-Institute of the MPG, Faradayweg 4-6, 14195 Berlin, Germany

* Corresponding author: e-mail dangsheng@ffhi-berlin.mpg.de, phone +49 308413 5406, fax +49 3084134405

\begin{abstract}
The application of analytical transmission electron microscopy in characterisations of catalytic materials is presented by studying the mechanically activated vanadium pentoxide $\mathrm{V}_{2} \mathrm{O}_{5}$. Local morphology and lattice distortion are studied by TEM while the oxidation states are determined by EELS. The mechanical activation can be described as a two-stage process: crushing of large crystals into small ones (macroscopic process) followed by amorphisation and reagglomeration of the fragments (microscopic process). No mill ing equilibrium state can be found. Energy-loss spectra reveal the reduction of vanadium via oxygen loss. The formation and distribution of $\mathrm{V}^{4+}$ or $\mathrm{V}^{3+}$ species depends on the history of milling.
\end{abstract}

Keywords: Catalysis, Microstructure, Oxidation state, defects, TEM, EELS

\section{Introduction}

It is well known that catalysis, the science and technology of the modification of the velocity of chemical transformations in selected reactions, is a surface phenomenon. A large amount of surface sensitive techniques, especially spectroscopic methods like XAS, XPS, IRS, UPS are applied in the research of catalytic materials. The question is therefore, how can (transmission) electron microscopy (TEM), which is in essence a bulk technique, be applied in catalysis to provide relevant information for the explanation of the catalytic mechanism. The first answer comes from the catalytic material itself: most catalysts are nanostructured as deposited cluster systems or as microstructured - mesostructured solids. Due to its high lateral resolution, a TEM provides an excellent access to the local morphology, crystallography and the composition of individual clusters or particles. Deposited clusters as small as $2 \mathrm{~nm}$ in size can be analysed via high-resolution imaging at a point resolution of less than $0,2 \mathrm{~nm}$. For solid-state oxide catalysts, the role of the bulk beneath the active centres of the surface is not very well understood. Possible diffusion of lattice oxygen towards the surface could play an important role. Also lattice defects, grain boundaries and shear structures - features which can very well be studied on a TEM - could be additional factors influencing the catalytic reaction.
The second answer comes from the electron microscope itself: an analytic electron microscope equipped with the facilities of EELS and EDXS is a powerful tool in elucidating the local electronic structure and chemical composition of the binary or ternary catalytic materials at nanometer scale. Since all catalytic processes concern the exchange of electrons between the reactants, information about the chemical valence and the local electron density of unoccupied states provided by core-level EELS becomes relevant. Due to the new development of monochromator and optimised spectrometers, high-energy resolution ELNES is available [1]. A comparison of bulk-sensitive ELNES with surface-sensitive NEXAFS could be interesting in order to proof the role of the bulk structure in catalysis.

One of the common methods in the structural characterisation in materials science is X-ray diffraction. Fig. 1 displays X-ray powder diffraction patterns of ball milled $\mathrm{V}_{2} \mathrm{O}_{5}$ samples, compared with that of untreated $\mathrm{V}_{2} \mathrm{O}_{5}$. Milling of $\mathrm{V}_{2} \mathrm{O}_{5}$ results in a decrease of integral intensities of individual Bragg peaks, an increase of the full width at half maximum, and an increase of the background of all milled samples. These features can be attributed to the reduction of particle sizes, the build-up of lattice defects and strain/stress in the bulk of the crystallites, and the increase of amorphous components in the milled powder. However, 


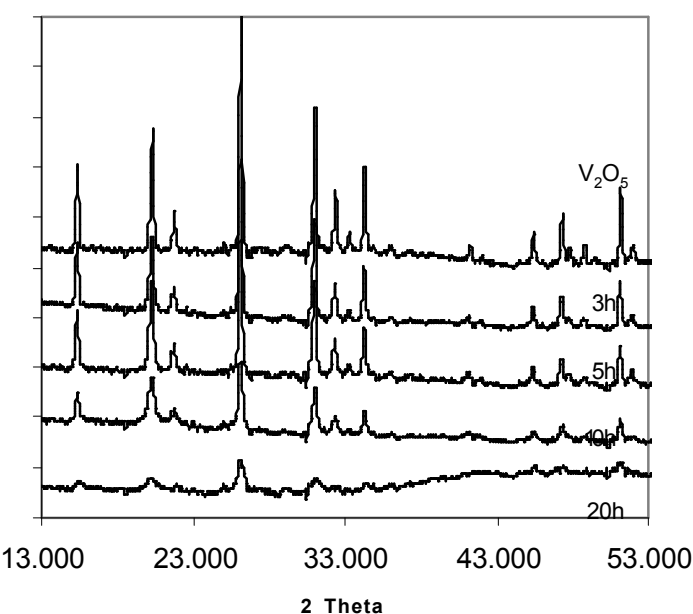

Figure 1. XRD of untreated and milled vanadium pentoxide

such valuable integral information needs to be complemented by experiments probing the nanoscopic structural range. Since the catalytic performance is strongly dependent on the microstructure and the electronic state of the surface of small particles, such investigations are also important for the development of more efficient catalysts. In the present work, we show, using mechanically modified $\mathrm{V}_{2} \mathrm{O}_{5}$ as an example, how TEM/EELS can be applied in the structural and chemical characterisation of catalytic materials.

In recent years, mechanical activation (usually by means of ball milling) has been widely used in catalyst research [2-4] for the preparation of metal oxide catalysts. Ball milling preparation, which is technically simple and environmentally friendly, can be performed either by the simultaneous grinding of two or more oxide powders, or by the milling of only one prior to mixing and calcination. In addition, ball-milling is an effective method for the modification of the defect structure and the electronic properties of catalytic materials. Improvements in the catalytic performance of ball-milled catalysts have been reported. For instance, the yield for $n$-butane oxidation to maleic anhydride (MA) increases by about $5 \%$ using a dry milled $\mathrm{V}_{2} \mathrm{O}_{5}$ precursor vs. the yield obtained with untreated $\mathrm{V}_{2} \mathrm{O}_{5}$, and yield increases even higher for wet milled $\mathrm{V}_{2} \mathrm{O}_{5}$ [3]. The catalytic performance of vanadyl pyrophosphate (VPP) catalysts is also influenced by ball-milling: the MA selectivity and maximum MA yields increase noticeably [4].

\section{Experimental}

Vanadium oxide $\mathrm{V}_{2} \mathrm{O}_{5}$ was from J. T. Baker Chemicals B. $\mathrm{V}$. and had a purity of $>99 \%$. Ball- milling was carried out in a planetary ball-mill: $60 \mathrm{~g}$ of $\mathrm{V}_{2} \mathrm{O}_{5}$ together with six agate balls $(1.5 \mathrm{~cm}$ diameter, $11 \mathrm{~g})$ were placed into an agate vessel $\left(250 \mathrm{~cm}^{3}\right.$ volume). Milling was performed for up to $20 \mathrm{~h}$ at approximately 150 revolutions per minute. Samples studied in the present work were taken after 3, 5, 10, and $20 \mathrm{~h}$.

For TEM investigations, untreated and milled samples were dispersed onto copper mesh grids covered with holey carbon films. A Philips CM200 FEG transmis- sion electron microscope, operating at $200 \mathrm{kV}$, and equipped with a GATAN image filter GIF100, was used. All selected area diffraction patterns are taken from an area of about 900 $\mathrm{nm}$ in diameter. The image filter, operated in the spectrosco-
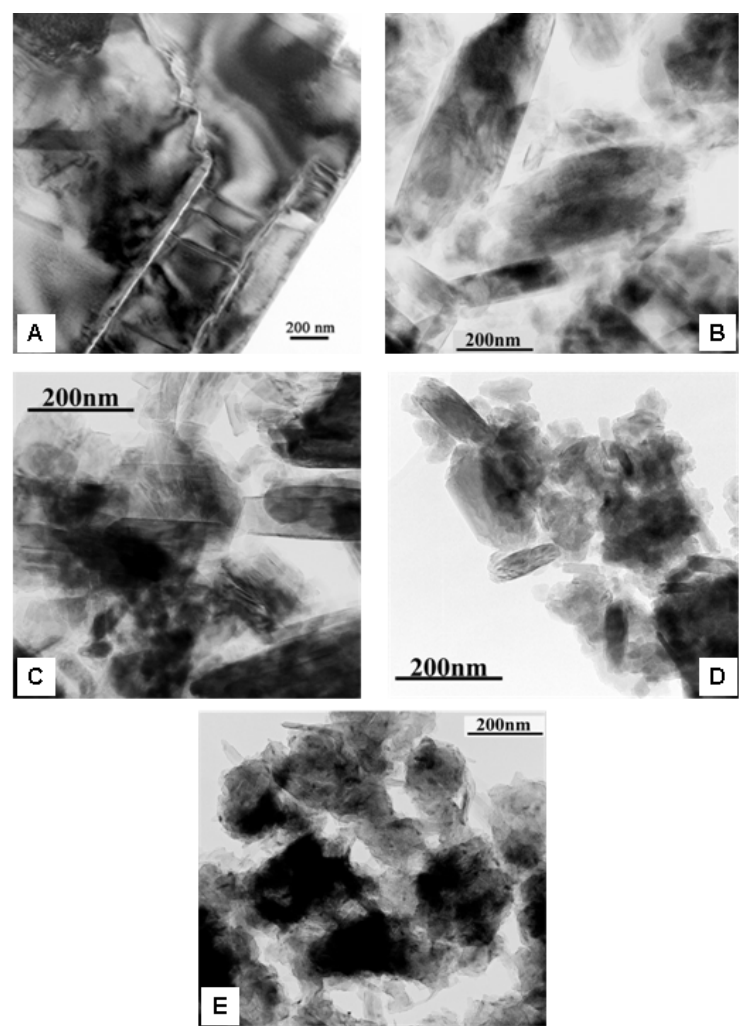

Figure 2. Electron microsgraphs of untreated and milled vanadium pentoxides

py mode, was used to record EELS-spectra. All spectra were recorded from very fine particles and from the thin edge area of large particles to avoid any artefacts due to large thickness, and were corrected for backgrounds and multiple scattering [5]. In order to avoid any artefacts such as electronbeam induced structural changes, high-resolution images were taken using electron dose as low as possible. EELSspectra were recorded with $2 \mathrm{~A} / \mathrm{cm}^{2}$ current density for $5 \mathrm{~s}$. According to a previous study about stability of $\mathrm{V}_{2} \mathrm{O}_{5}$ under electron beam irradiation, no chemical changes under those conditions are visible [6].

\section{Microstructure}

Electron micrographs of untreated and milled samples are reproduced in Figs. 2A - 2E. They reveal the morphological development of $\mathrm{V}_{2} \mathrm{O}_{5}$ and changes in the particle-size at various periods of milling in the planetary ball mill. Untreated $\mathrm{V}_{2} \mathrm{O}_{5}$ crystallite is shown in Fig. $2 \mathrm{~A}$. Up to $3 \mathrm{~h}$ the main effect of milling is the crushing of large crystallite (Fig. 2B). Further milling up to $10 \mathrm{~h}$ leads to the formation of fine particles whose size distribution becomes narrow and samples appear more homogenous in size (Fig. 2D). In Fig. $2 \mathrm{D}$ small particles of about $10 \mathrm{~nm}$ in size can be seen. Almost all particles exhibit a plate-like shape, as do those found in the untreated $\mathrm{V}_{2} \mathrm{O}_{5}$ sample. This confirms the find- 
ing by X-ray diffraction that fracture takes place in all directions [2]: the shape of particles up to $10 \mathrm{~h}$ milling time remains nearly the same, but their size decreases. The increasing of milling time up to $20 \mathrm{~h}$ leads to reagglomeration of small particles, the electron micrograph of the $20 \mathrm{~h}$ milled sample in Figs. 2E does not show clear profiles of individual particles. Some scarf-like contrasts were obtained, which was never observed in the samples milled for up to $10 \mathrm{~h}$.

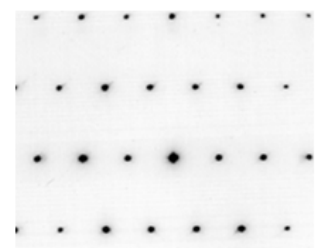

A

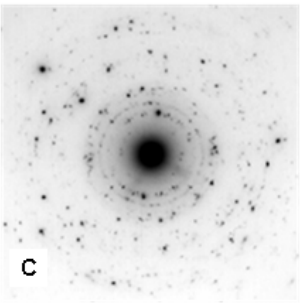

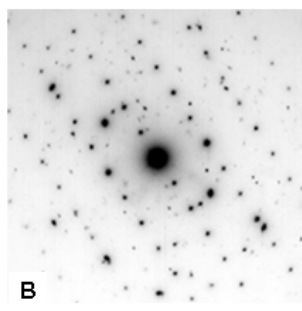

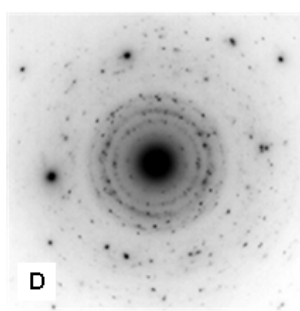

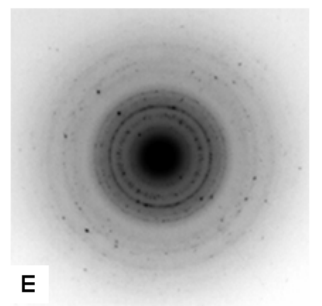

Figure 3. Selected area diffraction pattern of vanadium pentoxide: (A) as reveived $\mathrm{V}_{2} \mathrm{O}_{5}$; (B), (C), (D), and (E) ater 3, 5, 10 and $20 \mathrm{~h}$ milling, respectively.

Selected-area electron diffraction patterns in Figs. 3 reveal the drastic loss of internal structural ordering. The pattern in Figs. 3A can be identified as the 001-pattern of orthorhombic $\mathrm{V}_{2} \mathrm{O}_{5}$. While the pattern of the $2 \mathrm{~h}$ milled sample (Figs. 3B) still can be recognised as the 001-pattern decorated with additional spots due to the crushed particles, the pattern of the sample after $5 \mathrm{~h}$ milling (Figs. 3C) becomes speckled. After $10 \mathrm{~h}$ milling, rings made up of discrete spots appear in the diffraction pattern (Figs. 3D). Such discrete rings are formed when incident electrons are diffracted by randomly distributed nanoscopic particles. After milling for $20 \mathrm{~h}$, the diffraction pattern develops into a more continuous ring pattern since the long range ordering and particle sizes further decrease, reaching the level of amorphous matter (Figs. 3E). The diffuse background caused by the amorphous components in the samples becomes very prominent, especially in the pattern of the $20 \mathrm{~h}$ milled sample (Figs. 3E).
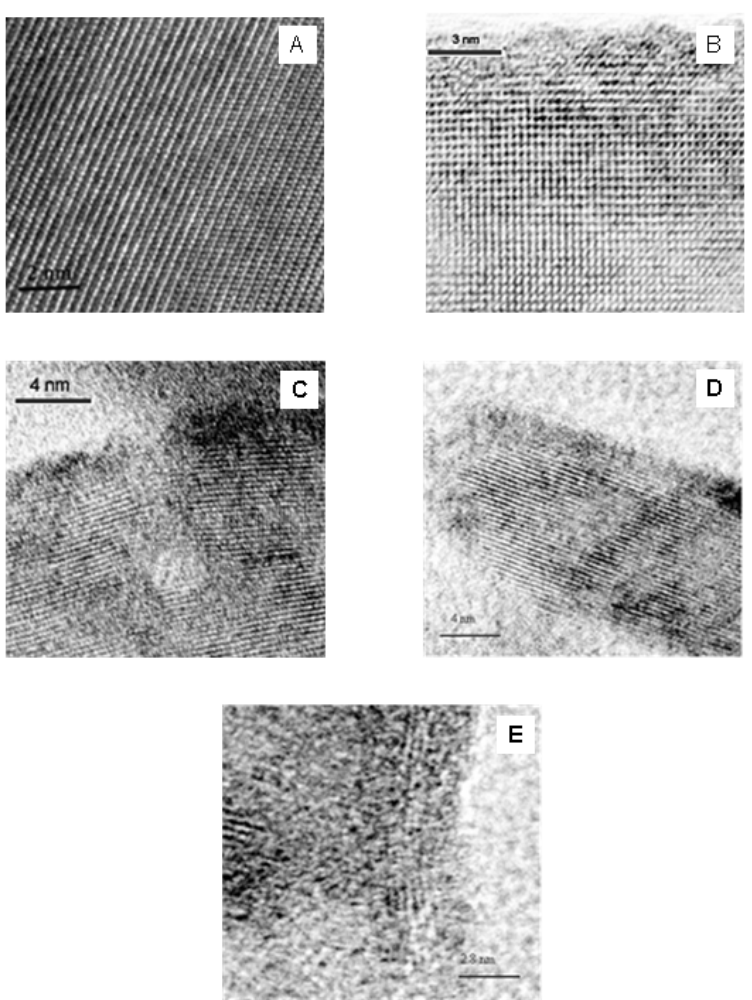

Figure 4. High-resolution images of vanadium pentoxide: (A) as reveived $\mathrm{V}_{2} \mathrm{O}_{5} ;(\mathrm{B}),(\mathrm{C}),(\mathrm{D})$, and (E) ater 3, 5, 10 and $20 \mathrm{~h}$ milling, respectively.

In order to know how the milling induces the change at an atomic scale, we recorded high-resolution lattice image from samples after various periods of milling. The image in Fig. 4A is from untreated $\mathrm{V}_{2} \mathrm{O}_{5}$, showing perfect lattice fringes without defects. Milling for $3 \mathrm{~h}$ induces disordered surface of particles (Fig. 4B). The image in Figs. $4 \mathrm{C}$ reveals the lattice breaking after $5 \mathrm{~h}$ milling. As the milling continues, particles are crushed and the lattice distortion becomes clearly visible (Figs. 4D). Nearly all investigated small particles of the $10 \mathrm{~h}$ milled samples show imperfect lattice fringes in high-resolution images. The image in Figs. $4 \mathrm{E}$, taken from the $20 \mathrm{~h}$ milled sample, shows a particle whose lattice has been nearly totally destroyed, representing a state before the particle becomes amorphous. Further milling will then lead to the complete amorphization of the particle and to the reagglomeration with other particles. The reagglomeration can take place as a relaxation effect to release the energy stored in the defect structures. It can even cause the formation of relarively large particles with irregular shape.

For understanding the amorphization and reagglomeration process during the prolonged milling time, we study the three typical high-resolution images in Fig.5. They reveal two kinds of contrast: (i) contrast with lattice fringes of small particles (Figs. 5A), most of them being less than 5 $\mathrm{nm}$ in size, aggregated to large particles as shown in the TEM-image in Figs. 3E and (ii) contrast that does not show any long-range order or periodic structures (Figs. 5B). This two-fold micro-morphology is the explanation of the overlay of continuous diffraction rings with small spots in the elec- 
tron diffraction patterns and of the strong background recorded both in X-ray diffraction and in electron diffraction patterns. An amorphous layer of about $5 \mathrm{~nm}$ in thickness can also be found on the surface of large particles (Figs. 5C). Careful investigation of the high-resolution micrographs in Figs. $5 \mathrm{~B}$ and $5 \mathrm{C}$ reveals the existence of short-range order (marked by circles) in the apparently amorphous regions. The platelets contain an irregular array of oxide clusters with a well-defined internal structure.

The knowledge gained by means of TEM, selected electron diffraction and high-resolution imaging cannot be obtained by integral methods such X-ray diffraction. TEM allows the access to the information about ball milling microscopically: what happens during milling and which effects it induces on the milled materials at nanoscale.

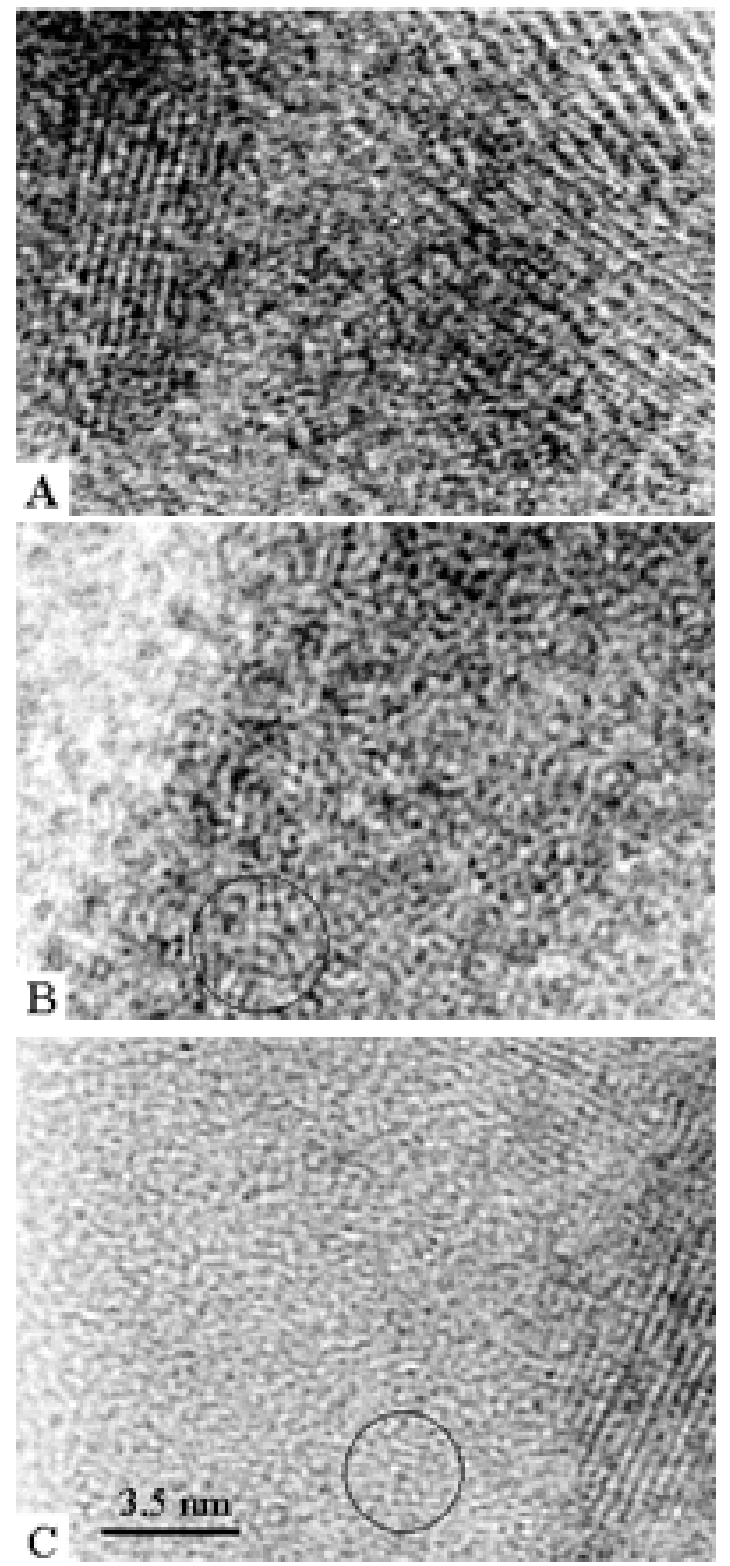

Figure 5 : High-resolution images of the vanadium pentoxide after $20 \mathrm{~h}$ milling: A, reagglomerated fine particle; B, amorphous part; $\mathrm{C}$, edge of a large particles. The circles in $\mathrm{B}$ and $\mathrm{C}$ mark areas with short-range order.

\section{Oxidation state}

The observed structural changes must be accompanied by chemical changes. EELS, which is nowadays standard facility on an analytic TEM, can be easily used to access to such information. Up to 10 energy-loss spectra of each sample at different positions were recorded. Vanadium $2 p$ spectra were then retrieved from the measured data. Typical spectra of samples after $3 \mathrm{~h}$ and $20 \mathrm{~h}$ milling, taken at different positions in each sample, are shown in Fig. 7, together with the spectrum of untreated $\mathrm{V}_{2} \mathrm{O}_{5}$. This spectrum is characterised by the vanadium $2 p \rightarrow 3 d$ transition ( $\mathrm{V} L$-edge): the two peaks, located at 519 and $525.7 \mathrm{eV}$, are the $\mathrm{V} L_{3}$ and $L_{2}$ edges, attributed to the transitions from the $\mathrm{V} 2 p_{3 / 2}$ and $\mathrm{V}$ $2 p_{1 / 2}$ core levels to the unoccupied V $3 d$ bands, respectively .

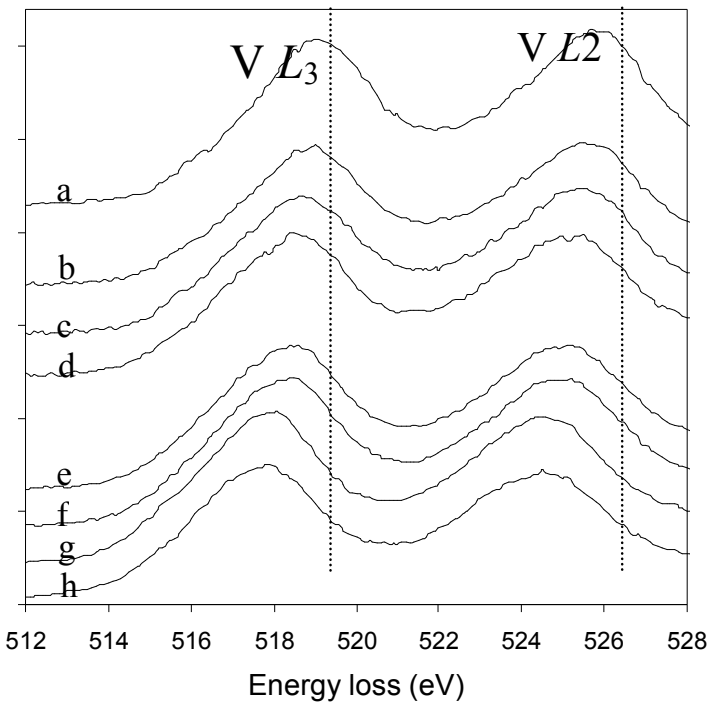

Figure 6. EELS-spectra of vanadium pentoxide: a, untreated; b-d, after $3 \mathrm{~h}$ milling; e-h, after $20 \mathrm{~h}$ milling.

In comparison with the spectrum of untreated $\mathrm{V}_{2} \mathrm{O}_{5}$, significant changes in the spectra of milled samples are shifts of the $\mathrm{V}_{2^{-}}$and $L_{3}$-edges to lower energy loss. These changes are evidence that milling induces the chemical reduction of vanadium ions. This reduction is caused by the loss of oxygen atoms caused by milling. A decrease of the intensity of $\mathrm{O} K$ edge was observed as milling time increases. The chemical shift depends on milling time. For samples milled for $3 \mathrm{~h}$ and $5 \mathrm{~h}$, spectra that are identical with the spectrum of untreated $\mathrm{V}_{2} \mathrm{O}_{5}$ can still be recorded. In spectra of the sample after $20 \mathrm{~h}$ milling the chemical shift of the $\mathrm{V} L_{2}$ - and $L_{3}$-edges to lower energy becomes significant. The chemical shifts measured for one sample at different positions vary, reflecting the chemical inhomogeneity of the samples introduced by milling. The measured $\mathrm{V} L_{3}$ edge positions of all milled samples are summarised in Table 1 . Using a correlation curve between the oxidation state of vanadium and the energy position of $\mathrm{V} \mathrm{L}_{3}$ edge [7], the oxidation states of vanadium ions after milling can be estimated (see Table 1). 
TABLE 1. $\mathrm{V} \mathrm{L}_{3}$ edge positions and oxidation states of untreated and milled vanadium pentoxides.

\begin{tabular}{|l|l|l|l|l|l|}
\hline Sample & $\mathrm{V}_{2} \mathrm{O}_{5}$ & $3 \mathrm{~h}$ & $5 \mathrm{~h}$ & $10 \mathrm{~h}$ & $10 \mathrm{~h}$ \\
\hline $\begin{array}{l}\text { V L3- } \\
\text { peak } \\
\text { positions }\end{array}$ & 519.0 & $\begin{array}{l}519.0- \\
518.7\end{array}$ & $\begin{array}{l}519.0- \\
518.6\end{array}$ & $\begin{array}{l}518.8- \\
518.2\end{array}$ & $\begin{array}{l}518.5- \\
517.8\end{array}$ \\
\hline $\begin{array}{l}\text { Oxidation } \\
\text { state }\end{array}$ & 5 & $5-4.3$ & $5-4.1$ & $4.8-3.7$ & $4-3.4$ \\
\hline
\end{tabular}

In Table 1 we can see that the sample milled for $3 \mathrm{~h}$ contains unreduced small particles (oxidation state 5) and reduced small particles (oxidation state 4.3). Milling up to 5 $\mathrm{h}$ induces further reduction of vanadium (down to 4.1), but unreduced particles can still be found. It is supposed that the unreduced particles in these two samples are formed during the milling by crushing of large particles. In the sample milled for $10 \mathrm{~h}$, however, all the analysed particles are reduced; the highest oxidation state is 4.6 and the lowest oxidation state is 3.7. Milling for $20 \mathrm{~h}$ gives rise to the total reduction of the $\mathrm{V}^{5+}$ state and only $\mathrm{V}^{4+}$ and $\mathrm{V}^{3+}$ states can be detected. The main effect of milling up to $5 \mathrm{~h}$ is therefore the crushing of crystallites into small ones, with a minor loss of oxygen. For milling up to $20 \mathrm{~h}$, the mechanical deformation and chemical reduction are equally effective. The inhomogeneity of oxidation states in all four milled samples can be explained as a dependence of the chemical state on the history of milling: the mechanical distortion of long range order is followed by a chemical reduction to a vanadium oxidation state below 5+ with two time constants in the order of several hours.

\section{Discussions}

Our investigation, performed by a combination of TEM and EELS, reveals that mechanical modification of $\mathrm{V}_{2} \mathrm{O}_{5}$ in a planetary agate ball mill can be divided into two stages, as illustrated in Fig. 7. The first stage ranges from initial milling to about $5 \mathrm{~h}$ where large particles are crushed, with a minor loss of oxygen. This is a macroscopic process of mechanical deformation and fracture. The second stage describes the transformations induced by extended milling times up to $20 \mathrm{~h}$ when particles undergo fine grinding and reduction. Lattice defects become severe and the size distribution tends to narrow. Finally, amorphisation and reagglomeration take place leading to scarf-like particles, accompanied by the reduction of $\mathrm{V}^{5+}$ in small particles to $\mathrm{V}^{4+}$ and $\mathrm{V}^{3+}$. This is a microscopic process that may have been ignored in earlier investigations. As revealed by highresolution imaging, amorphisation and reagglomeration occur in a nanoscopic size range. Physically, in the first period the energy supplied by ball milling is partly exhausted by crushing the crystallites. In the second period, the mechanical energy is partly stored as strain energy in particles. Most particles studied for this period show heavily deformed lattice. Therefore it seems that amorphisation and reagglomeration are consequences of extensive mechanical modification of $\mathrm{V}_{2} \mathrm{O}_{5}$.
By study the chemical changes of milled sample using EELS, another interesting phenomenon was observed in the present study: the inhomogeneity in all milled samples after various durations of milling. In particular, the formation of $\mathrm{V}^{4+}$ and $\mathrm{V}^{3+}$ species depends on the history of milling: the mechanical distortion of long range order takes place after several hours and the reduction starts at all milling times, although it becomes strong in the second stage mentioned above. Obviously mechanical modification of Vbased materials may not produce catalysts with homogenous chemical properties.
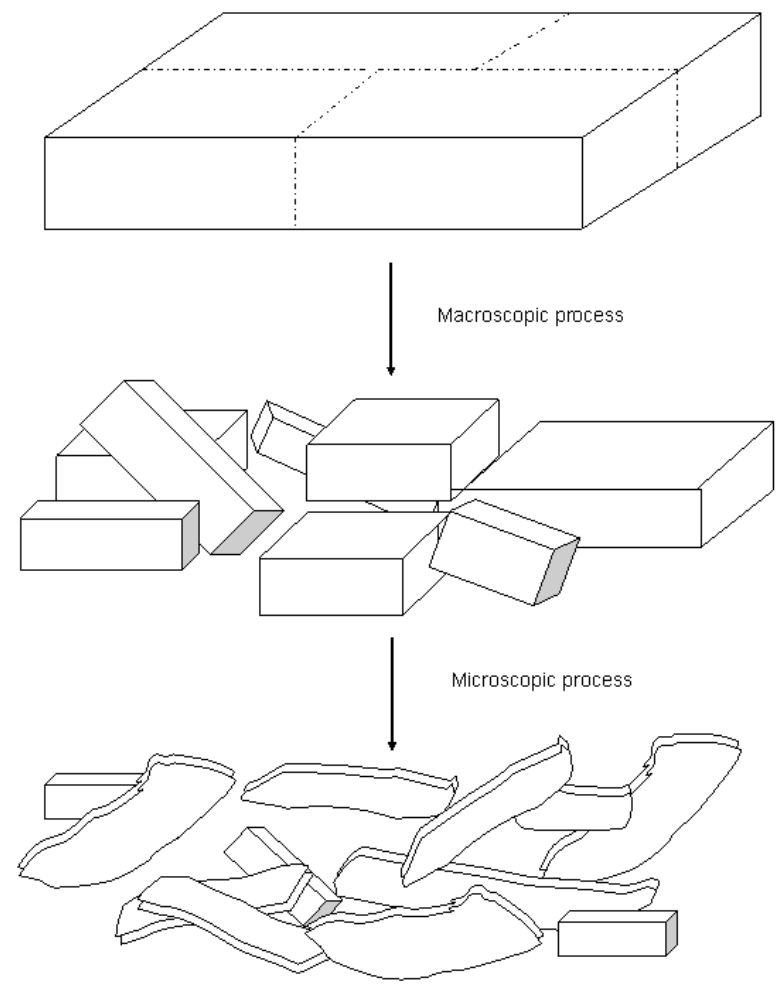

Figure 7. An illustration of the mechanical modification of $\mathrm{V}_{2} \mathrm{O}_{5}$. In the macroscopic process large particles are crushed into small ones. In the microscopic process amorphorisation and reagglomeration take place.

Milling equilibrium is reported for some vanadium oxide systems [4] where further milling causes only little macroscopic changes. Our results show, however, a continuos deformation and reduction of vanadium oxides at various periods of milling. Amorphisation and reagglomeration of particles take place. Therefore, the identification of a relevant parameter for controlling the milling becomes inevitable in the preparation of high performance catalysts. One criterion can be the abundance of $\mathrm{V}^{4+}$ centres or of phases containing vanadium in the $\mathrm{V}^{4+}$ state, since it was found that vanadium oxide systems containing both $\mathrm{V}^{5+}$ and $\mathrm{V}^{4+}$ in a suitable ratio and abundance exhibit the best catalytic performance [3].

The oxidation state of vanadium can also be determined by other methods such as ${ }^{51} \mathrm{~V}-\mathrm{NMR}$, EPR, and 
magnetic susceptibility measurements. However, all these methods, like X-ray diffraction, are integral methods and provide values averaged over a large number of particles. For instance, the average oxidation state of the sample after $20 \mathrm{~h}$ milling, determined by means of ${ }^{51} \mathrm{~V}-\mathrm{NMR}$ was found to be 4.8 [2]. This value is rather higher than the values summarised in Table 1. This is, however, no conflict to our results since the mentioned techniques do detect vanadium ions in the entire sample and do not provide information on the chemical state of vanadium within sub-micrometer regions. On the other hand, the present study does not analyse thick particles of the specimen. From the fact that our measurements were performed on very thin and small particles (less than $50 \mathrm{~nm}$ ), it can be concluded that vanadium ions in the bulk of large particles could still be in a high oxidation state close to 5. However, the increase of specific surface area, an expected effect of ball-milling and important for the catalytic performance $[2,3]$, is achieved mainly because of the existence of a large number of small particles, the oxidation states of which are changed in a microscopic process (Fig. 7).

\section{Summaries}

Using mechanically activated $\mathrm{V}_{2} \mathrm{O}_{5}$, we show the application of analytic TEM in evaluating the microstructure and local lateral resolution, provides not only a unique technique to access the information of catalytic materials at nanoscale. It delivers complete geometric structure information (SAED, HREM) that all the other analytic methods cannot provide. For the studied samples, the process of the activation of vanadium pentoxide $\mathrm{V}_{2} \mathrm{O}_{5}$ can be described as mechanical deformation (macroscopic process) followed by fine grinding, amorphisation and reagglomeration (microscopic process). No milling equilibrium state can be found. In the macroscopic process, the particle size decreases through fracture that takes place in all directions. Lattice defects are induced and the outer shell of most particles becomes amorphous. In the microscopic process small particles become completely amorphous and scarf-like particles grow through reagglomeration. Energy-loss spectra reveal the reduction of vanadium via oxygen loss. The formation of $\mathrm{V}^{4+}$ and $\mathrm{V}^{3+}$ species depends on the history of milling. In samples after $20 \mathrm{~h}$ milling, all studied small particles contain vanadium mostly in the $\mathrm{V}^{4+}$ and $\mathrm{V}^{3+}$ states.

\section{Acknowledgements}

The work at FHI is supported by SFB 546 of the Deutsche Forschungsgemeinschaft (DFG). The author thanks Prof. Knönziger for providing the samples and Prof. Schlögl for instructive discussion.

\section{References}

1. Tiemeijer P.C., van Lin J.J.A., and de Jong A.F. (2001) Monochromized 200 kV (S)TEM, Microsc. Microanal. 7(2), 1130-1131

2. Shubin A.A.,. Lapina O.B.N, Bosch E., Spengler J., and Knözinger H. (1999) Effect of Milling of $\mathrm{V}_{2} \mathrm{O}_{5}$ on the Local Environment of Vanadium as Studied by Solid-State ${ }^{51}$ V NMR and Complementary Methods, J. Phys. Chem. B 103, 3138-3144.

3. Zazhigalov V.A., Haber J., Stoch J., Bogutskaya L.V., Bacherikova I.V. (1996) Mechanochemistry as activation method of the V-P-O catalysts for n-butane partical oxidation, Applied Catalysis A: General 135, 155-161.

4. Fait M., Kubias B., Eberle H.-J., Estenfelder M., Steinike U. and Schneider M. (2000) Tribomechanical pretreatment of vanadium phosphates: structural and catalytic effects, Catal. Lett. 68, 13-18.

5. Egerton R (1996) Electron Energy-Loss Spectroscopy in the Electron Microscope, Plenum Press, New York. $262-269$.

6. Su D.S., Wieske M., Beckmann E., Blume A., Mestl G., and Schlögl R. (2001) Electron-beam-induced reduction of $\mathrm{V}_{2} \mathrm{O}_{5}$ studied by analytical electron microscopy, Catal. Lett. 75, 81-86.

7. Su D.S., Roddatis V., Wilinger M., Weinberg G., Kitzelmann E., Schlögl R., and Knözinger H. (2001) Tribochemical modification of the microstructure of $\mathrm{V}_{2} \mathrm{O}_{5}$, Catl. Lett. 74, 169-175. 